\title{
Imigração na Nação Espanhola
}

Ana Caballero Mengibar

Resumo: A literatura sugere que a Espanha nunca teve uma identidade nacional, mas um amálgama de identidades regionais. O ingresso na União Europeia e a chegada de imigrantes trazem novos desafios à identidade espanhola. Forjar uma identidade nacional implica em construir uma solidariedade baseada em "pertencimento" e excluir determinados grupos que podem constituir uma ameaça. A estas formas contemporâneas de exclusão, alinhadas com a imigração, pode-se chamar formações neo-raciais.

Palavras-chave: Imigração; Identidade nacional; Formação Neo-racial; Construção nacional.

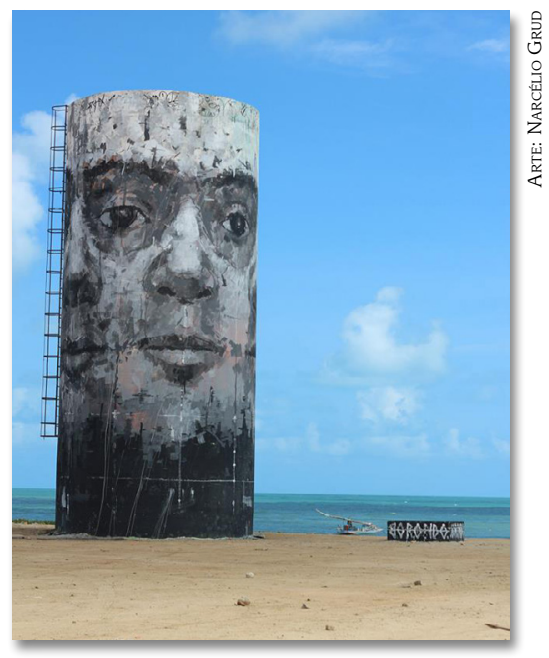

\section{Immigration In Spanish Nation}

Abstract: The literature suggests that Spain has never had a national identity but is rather an amalgam of regional identities. The accession to the European Union and the arrival of immigrants present new challenges to Spanish identity. Forging a national identity entails both building a solidarity based on 'belongingness' and excluding certain groups that might constitute a threat. These contemporary forms of exclusion aligned with immigration can be referred to as neo-racist.

Keywords: Immigration; National

\section{Ana Caballero Mengibar} identity, Neo-racial formation; Nation-building

Professora de Ciência Política na Universidade de Wisconsin Rock County, EUA.

ana.mengibar@uwc.edu

RECEBIDO EM 18-08-2014

Aprovado EM $14-04-2015$ 


\section{INTRODUÇÃO}

A persistência dos regionalismos periféricos espanhóis que datam do século XVII tem intrigado pesquisadores durante séculos, levantando a questão de se a Espanha tem, de fato, uma identidade nacional (BALFOUR; QUIROGA, 2007; BERAMENDI, 1992; LINZ, 1993; MURO-RUIZ; QUIROGA, 2005, p. 25; NÚÑEZ, 1993; NÚÑEZ, 2001; STAPELL, 2007). Isto contrasta com uma abundância de literatura especializada sobre os tópicos de nacionalismos regionais, particularmente regionalismos históricos, tais como o basco, o catalão e o galego. Outras formas não exóticas de nacionalismos periféricos, como na Andaluzia, Valência e Aragão, também têm recebido significantemente mais atenção (NÚÑEZ, 1993). Flynn (2001, p. 712) sugere que a falta de interesse em estudar a identidade hispânica como objeto em si também fica evidente no pequeno número de livrarias que contêm publicações sobre este assunto. A ênfase acadêmica no nacionalismo periférico entre 1975 e 1990 é provavelmente um dos motivos da escassez de historiografia sobre a questão nacional (STAPELL, 2007). Outras explicações podem incluir o desejo espanhol de esquecer rapidamente os 40 longos anos de identidade nacional opressiva e centralizada imposta pelo Estado, sob os desmandos de Francisco Franco (1939-1975) e seu regime fascista autoritário, e ao desejo da nação espanhola de fazer a transição para uma democracia bem-sucedida.

Os padrões migratórios contemporâneos têm complicado este debate. Desde fins da década de 1990, a Espanha experimentou “O mais rápido índice de imigração do mundo ocidental" (SAUNDERS, 2008, p. 1). Um relatório recente do Instituto de Política de Imigração argumenta que a "imigração não é percebida como uma ameaça para a identidade nacional [espanhola]... ela também poderia inferir que o nacionalismo espanhol está, ele mesmo, sob questionamento" (ARANGO, 2013, p. 12). A migração internacional causada pela globalização tem, como Castles e Miller (1998, p. 15) argumentam, aumentado a diversidade dentro das sociedades, apresentando uma série de problemas para o Estado. Um dos problemas mais sérios é o novo desafio à identidade nacional. Isto é ainda mais problemático em Estados nos quais a homogeneidade é imaginada "em termos de linguagem comum, cultura, tradições e história". 
Se declarações afirmam que a Espanha não tem uma identidade nacional, mas um amálgama de identidades e nacionalismos periféricos, os recentes movimentos migratórios representariam um desafio muito menor para o Estado espanhol, dado que, supostamente, não existem um senso de orgulho em ser espanhol e uma homogeneidade na 'Espanha'. Contudo, recentes mudanças na lei de imigração espanhola e mudanças na percepção dos imigrantes pelos hispânicos sugerem o contrário. Esta nova realidade levanta ainda mais questões sobre a identidade nacional espanhola.

O caso de estudo da Espanha proporciona um arcabouço que ajuda a esclarecer a questão de como o nacionalismo é formado, ao investigar se os padrões contemporâneos de imigração garantem coesão suficiente para unir a nação e para reimaginar sua identidade nacional. O caso também serve para ajudar a explorar se a construção da nação funciona mediante uma "re-imaginação" de fraternidade nacional horizontal, ou "espanidade"; e/ou excluindo seletivamente determinados grupos que não pertencem ao próprio imaginário coletivo. A imigração contemporânea tem moldado o discurso de "espanidade" de tal maneira que é possível agora vislumbrar na Espanha uma identidade nacional abrangente. A imaginação de uma identidade nacional é um processo em curso, que envolve a codificação da diferença entre 'nós' e 'eles' (DOTY, 2013). No entanto, discursos conflitantes de diferença e pertença, produzidos em um período de tempo específico, devem ser comumente aceitos como ameaças legítimas à existência de uma identidade imaginada primordial que visa vincular a nação a um destino percebido como comum. Porque a construção da nação nunca é um processo finalizado, discursos de pertença e exclusão devem coexistir, competindo diariamente para produzir a identidade nacional hispânica.

Narrativas históricas de "espanidade" e "alteridade" conflitantes sempre existiram no discurso de formação nacional na Espanha; mesmo assim, fracassaram em produzir um argumento inequívoco convincente de nacionalidade na Espanha, prevenindo, assim, uma fraternidade entre seus povos. Essa ausência de uma identidade nacional inequívoca e unificada, antes e depois de Franco, não deveria ser interpretada como a inexistência de uma identidade, 
mas como uma inabilidade em produzir discursos competitivos e convincentes de pertencimento e "alteridade", capazes de unir a nação espanhola. Contudo, uma identidade nacional espanhola, embora multifacetada, pode ser identificada.

\section{TEORIA DA CONSTRUÇÃO NACIONAL}

Pesquisadores continuam se esforçando para analisar e definir os processos de construção nacional (ANDERSON, 1983; BISHOP; JAWORSKI, 2003). Benedict Anderson introduziu o inovador termo "comunidade imaginada", em 1983, definindo o termo como uma "camaradagem horizontal". Mais tarde, ele explicou que as raízes culturais do nacionalismo residem nessa fraternidade. De acordo com Anderson (1983, p. 7), "em última instância, é essa fraternidade que tem possibilitado, no decorrer dos dois últimos séculos, que milhões de pessoas não apenas matem, mas também que estejam dispostas a morrer em nome de tais imaginações limitadas". O argumento de Anderson (1986) se referia especialmente ao papel do "capitalismo de imprensa" como meio de construir uma unidade de identificação para a nação, maior do que uma região, vila, ou comunidade local. Assim, a construção bem-sucedida de uma nação requer a construção de uma camaradagem horizontal.

Em um convincente argumento, Marx (2003) propõe que os nacionalismos modernos europeus surgiram como uma forma de engajamento político de massa, baseado em religião, conflitos, intolerância e exclusão. Discursos de exclusão, que coexistem com discursos de pertencimento, devem ter "inflexão" suficiente (MARX, 2003) para nacionalizar as pessoas com sucesso. O tipo de fraternidade horizontal que Anderson (1983) propõe nem sempre é exequível. Os tipos corretos de discursos concorrentes de inclusão e exclusão devem não apenas coexistir, mas também ganhar força suficiente um contra o outro de modo a criar um senso de unidade e pertencimento à nação.

Teorias contemporâneas de "neorracismo" argumentam que rotular um determinado grupo social como "culturalmente incompatível" tem levado ao surgimento de mais formas contemporâneas de exclusão. Pehrson e Green (2010, p. 696) colocam que 
[...] cidadãos nacionais podem demarcar fronteiras entre si e os imigrantes: 1) definindo a adesão ao grupo nacional, de modo que o foco esteja dentro do grupo; bem como, 2) apoiando critérios para a entrada de imigrantes, o que, mais diretamente, concerne às percepções daqueles que não pertencem ao grupo.

De acordo com Balibar (1991, p. 21),

[...] o tema dominante não é a hereditariedade biológica, mas a intransponibilidade das diferenças culturais, um racismo que, à primeira vista, não postula a superioridade de certos grupos ou povos em relação a outros grupos, "apenas" aponta os malefícios da extinção de fronteiras, e da incompatibilidade dos estilos de vida e das tradições.

A crescente migração de pessoas ao redor do mundo, um produto da globalização, faz das teorias "neo-raciais" uma opção interessante para a análise de como processos de inclusão e exclusão de imigrantes e nativos trabalham conjuntamente na construção da nação. Em democracias ocidentais contemporâneas, formações neo-racializadas de imigrantes vindos de países menos desenvolvidos podem trazer a força necessária para unir a nação em um momento em que a interdependência global está em seu ápice.

Uma abordagem teórica adequada, contudo, vê a construção nacional como resultado de discursos concorrentes, às vezes contraditórios, de inclusão e exclusão. No entanto, tais narrativas também podem levar a nações e Estados fragmentados, se eles não tiverem bastante "inflexão" unificadora (MARX, 2003). Narrativas e práticas exclusivistas alinhadas com imigração são unidades particularmente interessantes de análise porque elas possuem, inerentemente, a característica necessária para construir a fraternidade horizontal que está na raiz das origens do nacionalismo (ANDERSON, 1983). 


\section{CENÁRIO DOS DISCURSOS CONCORRENTES SOBRE A CONSTRUÇÃO DA NAÇÃO HISPÂNICA}

Desde a unificação da Espanha, no início do século XIV até princípios do século XVIII, a identidade espanhola tem sido construída em redor de características de religião "verdadeira" (o catolicismo romano), lealdade ao monarca e etnia primordial. Estas construções se tornaram aparentes logo depois da unificação alcançada pelos reis católicos sob os governos de Carlos de Habsburgo e Filipe II (ÁLVAREZ JUNCO, 2002, p. 15). A "espanidade" foi imaginada como produto do fato de ter uma história, cultura e características geográficas únicas. De acordo com Álvarez Junco (2002, p. 21), o argumento apresentado pelas elites foi o de que "desde tempos imemoriais, 'espanhóis têm sobrevivido a ondas e ondas de invasores, em sucessivos ciclos de perda e resgate da personalidade nacional".

No início dos anos 1800, as elites intelectuais espanholas buscaram reimaginar a identidade da Espanha através da inspiração de um nacionalismo revitalizado com a finalidade de modernização da sociedade e de seu sistema político. Naquele tempo, seguindo modelos europeus, os valores liberais que abrangiam os princípios da modernidade, do secularismo e do liberalismo foram introduzidos no discurso político, com o objetivo fundamental de estabelecer a Espanha como um Estado-nação verdadeiramente moderno. O congressista asturiano Agustin Arguelles clamou vitória durante sua introdução da primeira constituição espanhola liberal, de 1812, quando disse, "Espanhóis, agora vocês têm uma nação" (ÁLVAREZ JUNCO, 2001).

Desde o princípio, estes valores liberais modernos foram perturbadores em uma nação que, por tanto tempo, se alinhou com o catolicismo e a monarquia. Uma Espanha unificada sob princípios liberais modelando seus parceiros europeus ainda não era algo sustentável. Não demoraria muito para que a revogação da constituição liberal, por Fernando VII, forçasse intelectuais liberais a abandonar o país, e os valores católicos e monárquicos fossem relegitimados como os valores centrais da nação espanhola (LABANYI, 2004, p. 230). 
Como evidenciado em diversas revoluções daquele século, os liberais não desistiram por conta desta primeira derrota. A história da Espanha do século XIX em diante foi marcada por profundas crises políticas internas. A Espanha passou por três guerras civis no século XIX, além de uma terrível guerra no século XX (ÁLVAREZ JUNCO, 2002, p. 23). Depois das guerras napoleônicas no começo do século XIX, o poder político espanhol ficou significantemente degradado. Era óbvio que a Espanha não estava em paz com o restante da Europa.

Desde o Iluminismo, as outras nações foram construindo suas identidades através do uso da retórica da "superioridade da identidade europeia" (LABANYI, 2004, p. 231). Incapaz de participar deste discurso europeu, percepções de atraso e falta de progresso político-econômico e de modernização se tornaram predominantes dentro e fora da Espanha. As regiões mais industrializadas na Espanha, nomeadamente as regiões bascas e catalãs, associaram a falta de progresso espanhol com um senso de "fracasso", ao invés de orgulho de ser espanhol (ÁLVAREZ JUNCO, 2002, p. 24). Estas duas regiões começaram um processo de separação discursiva, seguindo diferentes caminhos de formação identitária. Elas buscaram se redefinir como sendo claramente diferentes do restante da Espanha.

Uma rejeição da espanidade foi ainda reforçada pela abundância de diversas tradições e festividades regionais, enquanto a Espanha tinha um processo fraco de criação de símbolos e mitos nacionais unificadores. Anderson (1983) mostrou que a impressão massiva de notícias nacionais lidas diariamente através da nação era crucial para a formação dos nacionalismos modernos. A Espanha tinha poucos jornais nacionais e a bandeira nacional não foi estabelecida até 1843 (ÁLVAREZ JUNCO, 2001).

No século XX, o general Franco orquestrou um golpe para "barrar a onda de liberalismo, secularismo e modernização na Espanha" (CASANOVA, 2010; GRAHAM, 2005; JERAM, 2013, p. 1775). O estabelecimento do regime autoritário de Franco na Espanha, depois de uma sangrenta guerra civil, em meados da década de 1930 (1936-1939) aprofundou a crise de identidade nacional. Narrativas concorrentes de construção nacional - modernização, 
a verdadeira religião, e valores europeus e monárquicos - se tornaram um sério problema. Enquanto Franco se dedicava a construir uma identidade supranacional centralizada e militarizada, várias regiões da Espanha, particularmente o País Basco e a Catalunha, estavam lutando para definir suas próprias identidades subnacionais. Franco acreditava que o ressurgimento do nacionalismo basco e catalão consistia numa ameaça não apenas à hegemonia da Espanha, mas também à construção de uma nação Castela étnica (pura); então, tentou suprimir estas identidades regionais (MURO-RUIZ; QUIROGA, 2005, p. 18).

As políticas fascistas franquistas não apenas suprimiram forçosamente qualquer expressão de identificação regional, incluindo a proibição do uso das linguagens regionais, elas também desencorajaram qualquer comparação da Espanha com a Europa ocidental. Isto dissuadiu ainda mais os pesquisadores de conduzir estudos sérios sobre a identidade nacional da Espanha, o que contribuiu para a falta de literatura sobre o tema.

Franco determinou que a Espanha era diferente (CARR, 200, p. 9). Ele arguiu que as tradições primordiais e culturais espanholas demandavam uma "trajetória política baseada na unidade nacional autoritária e sua herança católica" (GONZÁLEZ ANTON, 1998, p. 612-613). Inquestionavelmente, as ferramentas repressivas ainda débeis de Franco para nacionalizar as massas marcaram profundamente um país que tinha lidado com problemas de identificação e com a ideia de "España" provavelmente desde o século XIX (ÁLVAREZ JUNCO, 2002, p. 32).

A criação de uma nova democracia no Estado-nação espanhol após a morte de Francisco Franco demandava tanto um compromisso quanto um esforço de esquecimento do passado repressivo comum. Ao invés de encorajar uma memória nacional coletiva baseada nos abusos sofridos conjuntamente sob o regime fascista para construir uma unidade, os reformadores franquistas e a oposição exigiram acabar com as lembranças do passado, como formalizado pelos Atos da Anistia de 1976 e 1977 (FLYNN, 2001, p. 707). A amnésia política e social que encapsulou a Espanha desde a morte de Franco, impedindo uma unidade nacional em favor de uma identificação regional, foi imaginada sob a promessa 
de maior prosperidade, aumentando relações com a comunidade europeia. A Espanha agora foi reimaginada como uma nação mais secular, pluralista, composta de múltiplas identidades regionais, compartilhando pouca fraternidade homogênea e pronta para aceitar valores democráticos.

Símbolos como a bandeira e o hino nacional espanhóis continuam sendo associados com uma identidade nacional franquista centralizada e repressiva, mesmo depois da transição democrática. Uma "Nação de Nações" era a nova identidade espanhola de facto, e buscava deslegitimar a identidade nacional construída pelo regime fascista. Esta ideia, no entanto, foi ligada ao conceito de "nacionalismo constitucional" de Ortega y Gasset no começo do século XX (FLYNN, 2001, p. 710). De qualquer modo, esta unidade plural consistia em garantia de poderes aos vários governos regionais da Espanha.

O território espanhol foi dividido em 17 comunidades autônomas, "cada qual com seu próprio estatuto de autonomia e união regional, fazendo a unidade da nação espanhola ainda mais problemática" (STAPELL, 2007, p. 175). A descentralização do poder permitiu que as várias regiões se auto definissem. Muitas regiões na Espanha, notadamente o País Basco e a Catalunha, usaram linguagem, tradição e afinidade étnica como símbolos para se redefinirem. Descentralização como estratégia política não agradou de imediato as facções mais extremistas das regiões separatistas; o passado repressivo do regime franquista não era tão fácil de esquecer.

O Euskadi ta Askatasuna (ETA), no País Basco, tornou-se "a organização que personificou a variante radical do nacionalismo, por causa de seu comprometimento exclusivamente com a independência" (JERAM, 2013, p. 1776). Durante anos, catalães e bascos lutariam em busca de sua independência da Espanha. Entretanto, desde que a Espanha se tornou uma nova democracia, uma percepção não declarada de pertença compartilhada sempre esteve presente. O Artigo 2 da Constituição da Espanha de 1978 se refere à "unidade indissolúvel da nação espanhola". Como Garcia Casado (1987, p. 43) argumentou, "a nação espanhola não existe nem como uma realidade cultural nem como uma 
comunidade de indivíduos com uma identificação nacional forte e homogênea". Antes da entrada da Espanha na União Europeia em 1986, as narrativas de inclusão eram fracas e pouco convincentes para imaginar fortemente uma fraternidade horizontal unívoca. Em outras palavras, discursos concorrentes para a construção nacional não produziram o impulso necessário para uma unidade nacional que pudesse fazer o povo espanhol esquecer o legado do passado.

\section{QUEM PERTENCE À NAÇÃO?}

A ascensão da Espanha à União Europeia marcou uma nova fase na construção nacional. A Espanha experimentou um rápido progresso econômico, social e político, se tornando o destino preferido de imigrantes do mundo todo. Entre 2000 e 2009, a população estrangeira na Espanha mais do que quadruplicou, "indo de 1.5 milhões para mais de 6.5 milhões. Neste período, a parcela de imigrantes no total da população passou de $4 \%$ para quase $14 \% "$ (ARANGO, 2013, p. 2).

A rápida chegada de imigrantes, vindos particularmente de países mais pobres, expôs muitas das mudanças ocorridas na sociedade espanhola. A imigração tem inspirado de maneira crescente incidentes xenófobos e atitudes desfavoráveis em relação aos imigrantes (CHECA OLMOS; ARJONA GARRIDO, 2013). Movimentos migratórios globais contemporâneos trouxeram novos desafios à questão da identidade nacional e à lei de imigração na Espanha. A chegada de imigrantes de países mais pobres facilitou discursos concorrentes de exclusão e inclusão, causando grande impacto na unidade cultural da Espanha.

Desde que a Espanha fez a transição para a democracia, sua política tem sido modelada por dois principais partidos políticos - O Partidos Socialista dos Trabalhadores (PSOE, na sigla hispânica) e o Partido Popular (PP) (CALAVITA, 2005). Ambicionando se tornar um novo membro da União Europeia, e sem experiência ou preocupações com imigração, o PSOE criou a primeira lei de imigração, em 1985, mas isso apenas serviu para "aplacar os outros membros da União Europeia que estavam preocupados com a possibilidade 
de que a Espanha servisse como ponto de entrada na Europa para imigrantes indesejados" (JERAM, 2013, p. 1777).

A lei era muito restritiva: ela não garantia uma via legal de imigração para a Espanha, e impunha sanções contra imigração irregular. Várias regiões da Espanha reagiram contra esta lei restritiva, por diversos motivos. As cidades espanholas de Ceuta e Melilha, no norte da África, argumentaram que $1 / 3$ de suas populações eram de origem marroquina, e a lei tinha feito deles imigrantes ilegais. Depois de muitos protestos e demandas de nacionalização, um processo especial de acesso à cidadania foi garantido a ambas as cidades (GONZÁLEZ-ENRÍQUEZ, 2009, p. 140).

No início da história da imigração na Espanha, a lei de 1985 logo fez uma distinção entre dois grandes grupos: latino-americanos, filipinos, andorranos, guineenses equatoriais e judeus sefarditas, que tinham laços culturais e históricos reconhecidos com a Espanha; e aqueles que vieram da África, particularmente marroquinos. O primeiro grupo precisava residir por dois anos antes de requerer cidadania legal; o segundo grupo, por sua vez, era visto como não tendo essa conexão histórico-cultural imaginária e a lei requeria 10 anos para obtenção da cidadania. A exclusão dos marroquinos como pessoas sem ligações históricas com a Espanha é bastante irônica, dado que o Marrocos foi um protetorado espanhol de 1912 a 1956 (RIUS SANT, 2007). Esta forma de discriminação é consistente com formas mais contemporâneas de racismo, ou neo-racismo, no qual a incompatibilidade cultural constitui a base para a exclusão e o acesso desigual aos direitos.

Na década de 1990, o temor de uma aparente "avalanche" de imigrantes vindos para a Espanha, disseminado pela mídia e oficiais de governo, tornava-se uma preocupação crescente no país. Com o contínuo avanço da imigração, a região da Catalunha, nacionalista e separatista, queixava-se cada vez mais de que a lei era muito restritiva e que não garantia direitos sociais suficientes para a comunidade imigrante. O principal partido catalão, Convergencia i Unio (CiU) temia perder sua identidade, por isso, exigiu uma lei mais inclusiva e, em 1998, pressionou o Parlamento por mudanças. Eles planejavam assimilar imigrantes à região da Catalunha através do ensino do idioma e dos costumes. A crença 
subjacente era a de que os descendentes dos imigrantes seriam, se assimilados, indistinguíveis do resto da população (CASTLES; DAVIDSON, 2000, p. 60).

Em 2000, a imigração foi reconhecida como um fenômeno permanente e logo se tornou uma preocupação importante para toda a sociedade espanhola. Com o objetivo de controlar as indesejáveis consequências sociais desencadeadas por imigrantes irregulares não-europeus vindos particularmente da América Latina e da África Subsaariana, o PSOE, de centro-esquerda, propôs a lei $4 / 2000$, mais socialmente inclusiva. Movidos por temores fundamentados em mudanças sociais, a lei de cunho mais esquerdista proporcionou diversos direitos políticos e sociais aos imigrantes, tais como o direito à educação, saúde e seguridade social, a despeito de serem imigrantes legais ou ilegais. A lei também garantiu direitos políticos de associação, filiação sindical e manifestação, e tornou obrigatória a justificativa documentada por parte do Estado ante a negação de um requerimento de visto (JERAM, 2013, p. 1778). O discurso de garantia de mais direitos aos imigrantes foi concebido em torno "da possibilidade de disseminação de doenças contagiosas pelos imigrantes (havia rumores de reaparecimento da tuberculose), e para prevenir a delinquência juvenil entre imigrantes adolescentes matriculados na escola" (GONZÁLEZENRÍQUEZ, 2009, p. 142).

A nova lei foi criada com a coalizão de partidos que não faziam parte do governo e era mais social e politicamente inclusiva do que desejava o PP, partido governante de centro-direita. Sem uma visão sólida sobre imigração e sem maioria no Parlamento, o PP foi forçado a aceitar a nova lei. Sem muita experiência em lidar com a imigração e com uma cultura recente de inclusão democrática, espanhóis e a mídia reagiram de maneira positiva à lei; contudo, garantir direitos a imigrantes de modo a eliminar possíveis ameaças à sociedade e à sua identidade não durou muito - esta não era a política preferencial do PP.

A Lei $n^{\circ} 4 / 2000$, motivada pelo Partido Socialista, foi concebida entre 1985 e 1996, poucos anos antes do Conselho Europeu de Tampere, de 1999. Este Conselho marcou o início de uma abordagem global abrangente sobre a imigração na Europa. O Conselho 
estabeleceu três pilares para deter a crescente preocupação com a imigração na Europa: integração social dos imigrantes; controle de fluxos migratórios; e cooperação para o desenvolvimento dos países onde a imigração tinha origem, com a finalidade de reduzir a imigração para os países europeus (MARIN SANCHEZ, 2010, p. $3)$.

A crescente quantidade de imigrantes vindos de países menos desenvolvidos para a Espanha era uma grande preocupação para a Europa. A Espanha, agora um membro da União Europeia, era vista pelos outros membros como um participante-chave nas políticas de controle de imigração. Localizada no extremo sul da Europa, a Espanha é considerada uma porta para o restante da Europa. A chegada de imigrantes da América Latina e da África à Europa via Espanha fez emergir o debate que levou à criação da 8/2000, uma lei mais repressiva de reforma da imigração.

A nova e mais restritiva lei foi aprovada imediatamente depois que o partido de centro-direita PP venceu com maioria absoluta as eleições gerais em março de 2000. Essa lei tinha por objetivo lidar com a imigração e sua ameaça iminente através da proibição das liberdades civis fundamentais de direito de associação, manifestação e filiação sindical para todos os imigrantes legais da Espanha. Apenas em 2007 estas determinações foram declaradas inconstitucionais e corrigidas, na nova lei $2 / 2009$, no momento em que o centro-esquerdista PSOE controlava o governo. Não obstante, a lei 8/2000 restabeleceu a expulsão de imigrantes como punição por permanecer no país sem licença e aumentou a requisição de dois para cinco anos do tempo que um "migrante regular tinha que passar na Espanha de modo a regularizar sua licença de permanência" (GONZÁLEZ-ENRÍQUEZ, 2009, p. 144).

Durante esse período, de 200 a 2007, o comportamento dos espanhóis no tocante à imigração foi se tornando cada vez mais desfavorável. Percebeu-se que "sentimentos anti-imigrantes surgiam... as principais variáveis que explica[va]m este crescimento... [eram], por um lado, a ameaça definida pelo número de pessoas consideradas imigrantes e a perda da identidade nacional; e, por outro lado, a competição pelos recursos econômicos e sociais e os investimentos do Estado destinados à imigração" 
(CHECA OLMOS; ARJONA GARRIDO, 2013, p. 1). Vis-à-vis outros países europeus, no entanto, as atitudes da Espanha eram comparativamente positivas em relação aos imigrantes.

Por volta de 2007, o governo de tornou cada vez mais restritivo, como resultado da assim-chamada "Crise dos Cayucos" (um tipo de pequeno barco), quando, no verão de 2006, cerca de 25 mil imigrantes sem documentação chegaram às Ilhas Canárias a bordo desses barcos, depois de navegar pela costa da África Ocidental (GONZÁLEZ-ENRÍQUEZ, 2009, p. 150). Esse não foi um incidente isolado. A profunda crise econômica que estava emergindo se tornou aparente por volta de 2008, quando os indicadores econômicos revelaram o altíssimo nível de desemprego. Ao mesmo tempo, a União Europeia pressionou por "maior colaboração na luta contra a imigração ilegal proveniente da África" (GONZÁLEZENRÍQUEZ, 2009, 151) ${ }^{1}$. A crise econômica deu impulso ao discurso da imigração, e ambos os partidos políticos prometeram ser mais restritivos se a crise persistisse.

Antes da crise econômica de 2008, pesquisas indicavam que os espanhóis aceitavam amplamente a necessidade de ter a imigração como meio de impulsionar o crescimento econômico. Esta visão foi vastamente disseminada por ambos os partidos políticos dominantes e pela mídia. As atitudes dos espanhóis, bem como as diversas políticas nacionais, refletiram extensamente a crença infundada de que os imigrantes não estavam vindo para ficar permanentemente, mas para ocupar trabalhos indesejados (ARANGO, 2013). Os imigrantes eram vistos como mão-de-obra, não como pessoas que queriam encontrar uma residência permanente na Espanha. Em uma entrevista pessoal realizada em 2007 com Guervos Maillo, subdiretor do Ministério do Trabalho e Imigração da Espanha, o argumento era de que "Queremos que vengan extranjeros pero solo a rellenar los huecos que tenemos libres de mano de obra" ("Queremos que estrangeiros venham para a Espanha, mas apenas para preencher aquelas vagas de trabalho que precisam de trabalhadores") (GUERVOS MAILLO, 2007).

1 Para mais sobre o assunto, ver Marin Sanchez, 2010. 
Relatos aludindo ao preenchimento de trabalhos indesejados, em conjunção com o desejo da Espanha de tornar-se uma democracia inclusiva, podem explicar porque as atitudes espanholas eram mais receptivas aos imigrantes quando comparadas com as de seus parceiros europeus. Tais percepções e atitudes estabeleceram os fundamentos para a integração de imigrantes na sociedade espanhola. O escritório do Secretário-Geral de Imigração e Emigração não foi criado até 2011. Antes disso, questões de imigração eram administradas pelo Ministério do Trabalho, que mais tarde se tornou o Ministério do Trabalho e Imigração, quando imigrantes começaram a chegar na Espanha. Tratar os imigrantes em grande parte meramente como mão-de-obra não facilitou o acesso a oportunidades iguais. Este tratamento reforçou a ideia de que eventualmente eles voltariam aos países de origem depois que seu trabalho estivesse terminado, resultando em exclusão, ao invés de integração, e preservando uma suposta homogeneidade etno-cultural na nação.

Dado que a crise econômica levou a população nativa a taxas de desemprego de mais de $34 \%$, já não se podia afirmar que os trabalhadores imigrantes eram necessários ou que eles eram bons para a economia. A crescente percepção de que a imigração era permanente levou a discursos de exclusão que, abertamente, apresentavam a imigração como um fenômeno que não deveria ser permitido, pois traria significantes mudanças culturais e sociais para a nação (CASTLES; DAVIDSON, 2000). Durante as eleições de 2011, o conservativo PP viu essa como uma oportunidade de redefinir sua posição nacionalista na questão da identidade nacional. O Partido Popular não apenas prometeu políticas de imigração mais rígidas, mas também prometeu incluir políticas de assimilação e de exclusão para a integração e expulsão de imigrantes, se fosse eleito. Em seus vários discursos, Rajoy, líder do PP, foi claro ao afirmar que criaria políticas mais rigorosas do que aquelas defendidas por seu predecessor, Jose Luis Zapatero. Rajoy prometeu introduzir um "teste de integração".

Com sua esmagadora vitória nas eleições de 2011, o PP introduziu um teste de integração demandando aos imigrantes que queiram permanecer legalmente na Espanha por mais de um ano 
que demonstrem conhecer as normas, os costumes e o idioma espanhóis. Aqueles que requerem cidadania devem demonstrar capacidades similares. Até então, a noção espanhola de cidadania "não impôs uma identidade homogênea, mas se absteve de proclamar que multiculturalismo e diversidade são fontes de enriquecimento da sociedade espanhola" (JERAM, 2013, p. 1782). Este teste já foi contestado na corte.

La Audiencia Nacional ${ }^{2}$ negou, recentemente, cidadania a um cidadão equatoriano residente na Espanha. A corte negou sua solicitação de cidadania porque ele não pôde responder uma determinada quantidade de questões básicas sobre a Espanha. A corte determinou que a integração social consiste em mais do que apenas conhecer o idioma espanhol, a língua nativa do solicitante (EL PAÍs, 2013). Seguindo tendências europeias similares, as políticas de imigração na Espanha agora priorizam a integração, assimilação, controle de fronteiras, sentenças mais duras para o tráfico de imigrantes (GONZÁLEZ-ENRÍQUEZ, 2009, p. 151). A partir de agora, imigrantes terão acesso apenas a serviços médicos de emergência. O objetivo geral, de acordo com a administração, é deter novas chegadas de imigrantes enquanto durar a crise econômica.

Em suma, os discursos de inclusão e exclusão coexistem na nação espanhola. Discursos de imigração aludindo à ameaça de exclusão têm se tornado o centro para a reimaginação de uma identidade nacional espanhola, indicando que um senso de orgulho na espanidade pode ser identificado e provavelmente está crescendo na Espanha. Enquanto o que constitui espanidade permanece como uma controvérsia, o "eu" espanhol consiste de uma identidade de certo modo pós-moderna, diversa, homogênea, que compartilha uma herança cultural comum (STAPELL, 2007). A ideia de uma espanidade homogênea que coexiste com uma diversidade interna regional ganha força quando contrastada com um "outro" imaginário rotulado de imigrante que não compartilha uma herança cultural e histórica imaginária comum.

2 NT: "La Audiencia Nacional de España" tem sede em Madrid e exerce jurisdição sobre todo o território espanhol. 


\section{CONCLUSÃO}

O desenvolvimento e a persistência dos nacionalismos periféricos no fim do século XIX não prova que uma identidade nacional abrangente não pode ser identificada na Espanha. Como Álvarez Junco (2002, p. 15) argumenta, os nacionalismos basco e catalão são apenas o produto do "fraco esforço para nacionalizar as massas, ou do processo incompleto de construção nacional, em termos hispânico-catalães, durante o século XIX". Em outras palavras, construir uma nação que exclui determinadas expressões étnicas e regionais tem o efeito oposto. A construção nacional é um processo fluido e sempre em evolução. No caso da Espanha, a exclusão inicial dos não católicos, seguida pela rejeição de valores liberais e, mais tarde, a exclusão de identidades subnacionais serviram para reimaginar várias noções de espanidade, contudo, nenhuma levou a uma bem-sucedida construção nacional na Espanha.

Com a chegada dos imigrantes e a ascensão da Espanha à União Europeia, um grupo claramente representado como "não-pertencente" ao ambiente cultural da Espanha pode ser identificado mais facilmente agora. Quem pertence a "nós"? Recentemente, estas questões se tornaram, novamente, de grande importância para a nação espanhola. Discursos concorrentes de imigração desafiam até certo ponto o argumento de Anderson, de 1983, sobre o processo de formação nacional como uma "camaradagem horizontal". O Estado espanhol aparentemente experimentou um conflito com a ideia de imaginar uma "fraternidade horizontal". O objetivo definitivo do Estado é encontrar um "eu" unificado contra o "outro". Por esta razão, práticas e argumentações que se referem à assimilação coexistem com aquelas de exclusão. Além disso, e mais importante, o "eu" espanhol é construído como uma entidade com um "pertencimento" cultural e histórico compartilhado.

Reimaginar uma unidade nacional implica forjar uma solidariedade baseada no "pertencimento" e/ou em uma "camaradagem horizontal", ao mesmo passo em que, simultaneamente, exclui determinados grupos. Ao criar um senso de unidade na Espanha contemporânea, foi essencial apresentar os imigrantes como uma ameaça à economia e à herança cultural da Espanha, de modo a 
forjar um senso de unidade nacional capaz de superar as identidades regionais. Para construir uma coesão nacional, como Marx (2003, p. 75) sugere, uma forma de exclusão deve ter força de "inflexão" suficiente para abranger divisões regionais; a exclusão de grupos seletivos de imigrantes na Espanha parece ter tal força ou "inflexão".

Ao mesmo tempo, nem todos os grupos imigrantes são igualmente impedidos de se juntar à unidade nacional. Dada a fluidez da nação para se reimaginar, práticas de inclusão e assimilação de grupos excluídos proporcionam pequenos espaços abertos para incorporar imigrantes seletos a esta unidade fraterna horizontal. Este dinamismo facilita o espaço para a constante reimaginação da nação.

Incorporar imigrantes à nação imaginada horizontal ou fraternalmente é um processo bastante seletivo, visto que nem todos os imigrantes lograrão se qualificar para serem assimilados, e o processo é complexo. Mas, acima de tudo, Breuilly (1982, p. 1-2) lembra que nacionalismo trata de política, e política diz respeito a poder, e poder, "no mundo moderno[,] é, principalmente, controle do Estado".

Tradução: Camila Alves da Costa e Mônica Dias Martins

\section{REFERÊNCIAS}

ÁLVAREZ JUNCO, J. The formation of Spanish identity and its adaptation to the age of nations. History \& Memory, v. 14, n. $1 / 2$, p. 13, 2002.

Mater dolorosa: La idea de España en el siglo XIX. Madrid: Taurus, 2001.

ANDERSON, B. The cultural roots of nationalism. In: DONALD, J.; HALL, S. (Eds.). Politics and Ideology. Philadelphia: Open University Press, 1986. p. 88-104.

Imagined communities: reflections on the origin and spread of nationalism, London \& New York: Verso, 1983. 
ARANGO, J. Exceptional in Europe? Spain's experience with immigration and integration. Madrid: Migration Policy Institute, Complutense University of Madrid, 2013. Disponível em: <http:// www.migrationpolicy.org/pubs/TCM-Spaincasestudy.pdf>. Acesso em: 6 jan. 2014.

BALFOUR, S.; QUIROGA, A. The reinvention of Spain: nation and identity since democracy. New York: Oxford University Press, 2007.

BALIBAR, E. Is there a 'neo-racism'?. In: BALIBAR, E.; WALLERSTEIN, I. (Eds.). Race, Nation, Class. London: Verso, 1991. p. 17-28.

BERAMENDI, J. La historiografía de los nacionalismos en España. Historia Contemporánea, v. 7, p. 135-154, 1992.

BISHOP, H.; JAWORSKI, A. 'We Beat 'em: nationalism and the hegemony of homogeneity in the British discourse press reportage of Germany versus England during Euro 2000. Society, v. 14, p. 243, 2003.

BREUILLY, J. Nationalism and the State. Manchester: Manchester University Press, 1982.

CALAVITA, K. Immigrants at the margins: law, race, and exclusion in Southern Europe. New York: Cambridge University Press, 2005.

CARR, R. Introduction. In: (Ed.). Spain: a history. Oxford: Oxford University Press, 2000. p. 1-9.

CASANOVA, J. The Spanish Republic and civil war. New York: Cambridge University Press, 2010.

CASTLES, S.; DAVIDSON, A. Citizenship and migration: globalization and the politics of belonging. New York: Routledge, 2000 .

CASTLES, S.; MILLER, M. The age of migration: international population movements in the modern world. New York: Guilford Press, 1998.

CHECA OLMOS, J. C.; ARJONA GARRIDO, A. LOs immigrantes vistos por los espanoles: entre la amenaza y la competencia (1997-2007).

Revista de Estudios Sociales, v. 47, p. 118-132, 2013. 
DOTY, R. Anti-Immigrantism in western democracies statecraft, desire, and the politics of exclusion. New York: Routledge, 2003.

EL PAÍS. La Audiencia niega la nationalidad a un discapacitado psiquico de Ecuador. Disponível em: <http://sociedad.elpais.com/ sociedad/2013/11/25/ actualidad/1385414364_417572.html>. Acesso em: 25 nov. 2013.

FLYNN, M. Constructed identities and iberia. Ethnic \& Racial Studies, v. 24, n. 5, p. 703-718, 2001.

GARCIA CASADO, S. Algunas reflexiones acerca del problematico naionalismo espanhol. Cuadernos de Alzate, v. 5, n. 1, p. 37-44, 1987.

GONZÁLEZ ANTON, L. España y las Españas. Madrid: Alianza, 1998.

GONZÁLEZ-ENRÍQUEZ, C. Spain, the cheap model. Irregularity and regularisation as immigration management policies. European Journal of Migration \& Law, v. 11, n. 2, p. 139-157, 2009.

GRAHAM, H. The spanish civil war: a very short introduction. New York: Oxford University Press, 2005.

GUERVOS MAILLO, Carlos. Interview by author. [Madrid]: Subdirector del Ministerio de Trabajo y Asuntos Sociales in Spain, 2007.

JERAM, S. Immigrants and the basque nation: diversity as a new marker of identity. Ethnic and Racial Studies, v. 36, n. 11, p. 1770-1788, 2013.

LABANYI, J. Love, politics and the making of the modern European subject: Spanish romanticism and the arab world. Hispanic Research Journal, v. 5: 3, p. 229-243, 2004.

LINZ, J. Los nacionalismos en España: una perspective comparative. In: D'AURIA, E.; CASSASAS, J. (Eds.). El estado modern en Italia y España. Barcelona: Universitat de Barcelona, 1993.

MARIN SANCHEZ, I. Desvelando el desarrollo en regiones migratorias: Contribuciones al debate sobre migración y desarrollo desde Marruecos y México. [S.1.]: Center for Migration and Development, 2010. p. 1-27. (Working Paper Series 11-01). 
Disponível em: <http://www.princeton.edu/cmd/workingpapers/>. Acesso em: 2 jan. 2014.

MARX, W. A. Faith in nation: exclusionary origins of nationalism. New York: Oxford University Press, 2003.

MURO-RUIZ, D.; QUIROGA, A. Spanish nationalism: ethnic or civic? Ethnicities, v. 5, n. 1, p. 9-29, Mar. 2005.

NÚÑEZ, X. What is Spanish nationalism today? From legitimacy crisis to unfulfilled renovation. Ethnic and Racial Studies, v. 24, n. 5, p. 719-752, 2001.

. Historiographical approaches to nationalism in Spain.

Saarbruchen: Breitenbach, 1993.

PEHRSON, S.; GREEN, E. Who we are and who can join us: national identity content and entry criteria for new immigrants, Journal of Social Issues, v. 66, n. 4, p. 695-716, 2010.

RIUS SANT, X. El libro de la immigracion en España. Spain: Almuzara, 2007.

SAUNDERS, D. Spanish lessons: Who can define integration? The Globe and Mail and division of CTV, 2008.

STAPELL, H. Reconsidering Spanish nationalism, regionalism, and the centre-periphery model in the post-Francoist period, 19751992. International Journal of Iberian Studies, v. 20, n. 3, p. 171185, p. 2007. 